\title{
Health survey of former workers in a Norwegian coke plant: part 1. Estimation of historical exposures
}

\author{
P R Romundstad, A Rønneberg, H L Leira, T Bye
}

\begin{abstract}
Objective-To estimate historical exposure levels at a coke plant for all agents considered to be of importance for epidemiological studies of mortality and cancer incidence.

Methods-Time weighted average exposure ( 8 h TWA) was estimated based on personal measurements for polycyclic aromatic hydrocarbons (PAHs) and carbonaceous particulates. Exposure to quartz was estimated relative to the concentration of carbonaceous particulates. These estimates were adjusted for the use of airstream helmets. Exposure to other agents were estimated qualitatively (asbestos, benzene, and arsenic) or semiquantitatively (carbon monoxide (CO) and heat) based on measurements and other indicators of exposure.
\end{abstract}

Results-Exposure to PAHs was highest for those who worked at the top of the ovens $\left(300 \mu \mathrm{g} / \mathrm{m}^{3}\right)$ in the period from 1970-6. The estimated PAH exposure was reduced to an average of $65 \mu \mathrm{g} / \mathrm{m}^{3}$ after the introduction of exposure control measures in 1976. The estimates for carbonaceous particulates ranged from 1 to 16 $\mathrm{mg} / \mathrm{m}^{3}$, with the highest exposure for workers at the top of the ovens and at the coke screening station.

Conclusions-The exposure of greatest concern in this study is to PAHs, but exposures to carbonaceous particulates and CO may also be of importance. The major limitations of this study are the lack of personal measurements before 1975 and the total lack of measurements for some of the exposed categories of workers. Despite these limitations, we think that this assessment reflects the actual exposures for most of the former employees. The assessment thus provides a reasonable tool for the subsequent epidemiological study and for future epidemiological follow up studies at the coke plant. (Occup Environ Med 1998;55:616-621)

Keywords: exposure assessment; coke production; polycyclic aromatic hydrocarbons

Norway

A Rønneberg, died May 1997

Correspondence to: Dr PR Romundstad,

Department of Occupational

Medicine, University

Hospital of Trondheim,

Norway.

Accepted 16 April 1998

Recently, increased focus has been placed on the estimation of exposure for use in epidemiological studies, and several methodological papers have been published. ${ }^{1-3}$ The need for validation of the estimation procedure has been pointed out, but validation is usually difficult owing to the lack of representative measurements of historical exposures. A transparent documentation of the estimation procedure may add credibility to the results under such circumstances.

This study concerns a Norwegian coke plant which operated from 1964 to 1988. As in earlier studies in coke production plants, ${ }^{4-8}$ considerable exposure to coal tar pitch volatiles (CTPV) containing polycyclic aromatic hydrocarbons (PAHs) has been reported from the study plant. ${ }^{9}$ Previous epidemiological studies concerning coke plants have considered $\mathrm{PAH}$ as the only relevant exposure. In the present study we also included exposure to asbestos, carbonaceous particulates, quartz, arsenic, benzene, carbon monoxide (CO), and heat. The estimation of exposure was part of a study of current health, cancer incidence, and cause specific mortality among the former employees.

\section{Material and methods}

THE PRODUCTION PROCESS

The study plant produced quartz coke for the ferrosilicon industry and reactive coke for a pig iron smelter. Coke is the residue from the destructive distillation of coal in the absence of oxygen. Ammonia, benzene, coal tar, and sulphur are byproducts. The plant included a coke production area (coke side) and a gas refining area (gas side). The coke ovens were charged from the side until 1970 when they were rebuilt for top charging. After the coal had been heated for about 17 hours, a ram car pushed the coke sideways out of the ovens through a coke guiding car and into a quenching car. The coke was then transported through a quenching tower where it was sprayed with water to stop further combustion.

The coke gas was funnelled from the ovens to the gas refining area where coal tar was removed by cooling with water. Inorganic sulphur was removed by scrubbing the gas with a solution of arsenic and potash. Benzene was extracted with a light oil. Methane and heavier hydrocarbons were cracked and converted into hydrogen and carbon dioxide $\left(\mathrm{CO}_{2}\right)$. A synthesis reactor transformed the remaining gas mixture into ammonia $\left(\mathrm{NH}_{3}\right)$ after compression and the removal of $\mathrm{CO}$ and $\mathrm{CO}_{2}$, and the addition of nitrogen from air.
NDUSTRIAL HYGIENE DATA

Table 1 shows the available industrial hygiene data. The personal measurements included about 594 samples of particulate PAHs and 124 samples of total carbonaceous particulates. 
Table 1 Measurement data from the coke plant

\begin{tabular}{lccl}
\hline Agent & $\begin{array}{l}\text { Personal } \\
\text { samples } \\
(n)\end{array}$ & $\begin{array}{l}\text { Area } \\
\text { samples } \\
(n)\end{array}$ & $\begin{array}{l}\text { Sampling } \\
\text { period }\end{array}$ \\
\hline PAHs & 594 & - & $1976-87$ \\
Carbonaceous particulates & - & 66 & 1976 \\
Quartz content & - & - & $1974-87$ \\
Arsenic & 31 & 47 & $1970-75$ \\
Carbon monoxide & 9 & 33 & 1974,1979 \\
Benzene & - & 49 & 1975,87 \\
\hline
\end{tabular}

Polycyclic aromatic hydrocarbons were sampled on membrane filters and analysed by gas chromatography until 1980 when this method was replaced by thin layer chromatography. ${ }^{9} 10$ Total carbonaceous particulates were collected on filters and analysed by gravimetry. Quartz and arsenic were analysed by infrared spectroscopy and atomic absorption spectroscopy, respectively. Benzene and $\mathrm{CO}$ were measured with indicator tubes (Dräger). The representativeness of these previous measurements was considered with respect to measurement strategy and reason for sampling. Only personal measurements of PAHs and total carbonaceous particulates sampled for $\geqslant 4$ hours were used to quantify exposures directly. About $7 \%$ of the samples of PAHs and carbonaceous particulates were discharged due to possible worst case sampling or short sampling time.

\section{GROUPING OF JOBS}

Of the 824 workers with $>1$ year of total employment, who were alive in 1993, 628 answered a questionnaire and 515 were also interviewed by an industrial hygienist (PRR). A guide was constructed for the interview. Information was collected about personal exposure in different jobs over time and about the use of protective devices.

An exposure profile was constructed for each job at the plant with information from the plant records, the interviews, and the questionnaires. The job exposure profiles and the relevant industrial hygiene data were then used for the grouping of jobs into exposure categories. We estimated exposures for each category in different periods based on changes in the production process, the work practices, and the use of protective measures. In this study, the term exposure category designates one ore more jobs associated with a location-such as coke oven top - an operation-such as coal treatment-equipment-such as stamper car-or a function - such as supervisor.
EXPOSURE TO PAHS

The exposure of the workers to PAHs at the ovens was estimated from the arithmetic means of personal measurements. ${ }^{11}$ Air stream helmets were used from 1977 and onwards. Data from personal measurements inside and outside the air stream helmets and information from the interviews about their use made it possible to adjust the exposure estimates. The measurement of exposure to PAHs before 1970 had to be based on interview data and supported by measurements from other coke plants with side charging. ${ }^{78}$

The collection of repeated samples of PAHs for the top oven workers and the side oven workers permitted estimation of within worker variance ${ }_{\mathrm{ww}} \mathrm{S}_{\mathrm{y}}{ }^{2}$ and between worker variance ${ }_{\mathrm{BW}} \mathrm{S}_{\mathrm{y}}{ }^{2}$ with a one way analysis of variance (ANOVA). ${ }^{11-14}$ The effect of using air stream helmets was also evaluated. The range of exposures experienced among workers in each category was estimated through the ratio of the 97.5 and 2.5 percentiles of the log normally distributed exposures as ${ }_{\text {вш }} \mathrm{R}_{0.95}=\exp (3.92$ $\left.{ }_{B \mathrm{~W}} \mathrm{~S}_{\mathrm{y}}\right) .^{12}$

As the data fitted a log normal distribution, the statistical analyses were performed with the natural logarithm of the measurement data. Geometric means were calculated by taking the exponential of the mean of the logarithm of the measurements. ${ }^{11}$ The $95 \%$ confidence intervals (95\% CIs) for the means were calculated assuming a $t$ distribution. SPSS/PC+, version 5.0 was used in all the statistical analyses.

\section{OTHER EXPOSURES}

Time weighted average exposures ( $8 \mathrm{~h}$ TWAs) were estimated for carbonaceous particulates with the arithmetic means of the personal measurements for the different exposure categories.

The content of quartz in carbonaceous particulates was measured in 78 samples. These measurements were used to suggest quartz exposure by exposure to carbonaceous particulates.

The number of hours spent at mixing arsenic at the sulphur cleaning department was estimated for the exposure categories involved. These estimates were used together with short time personal measurements, to suggest the likely arsenic exposure at the sulphur cleaning department, assuming no exposure in periods when arsenic was not mixed.

Table 2 Descriptive statistics of personal measurements of PAHs $\left(\mu \mathrm{g} / \mathrm{m}^{3}\right)$ in different periods for the coke oven categories at the coke plant

\begin{tabular}{|c|c|c|c|c|c|}
\hline Exposure category (period) & $\begin{array}{l}\text { Measurements } \\
\text { (n) }\end{array}$ & $\begin{array}{l}\text { Arithmetic } \\
\text { mean (SD) }\end{array}$ & $95 \% C I$ & $\begin{array}{l}\text { Geometric } \\
\text { mean } \\
(G S D)\end{array}$ & $95 \% C I$ \\
\hline \multicolumn{6}{|l|}{ Top oven: } \\
\hline 1976 & 12 & $300(254)$ & 139 to 461 & $237(2.1)$ & 151 to 370 \\
\hline $1978-87$ & 221 & $125(91)$ & 113 to 138 & $100(2.0)$ & 91 to 110 \\
\hline Inside airstream helmets $1977-87$ & 212 & $37(32)$ & 33 to 41 & $26(2.5)$ & 23 to 29 \\
\hline \multicolumn{6}{|l|}{ Side oven: } \\
\hline $1976-87$ & 75 & $44(83)$ & 25 to 63 & $25(2.5)$ & 20 to 31 \\
\hline Inside air stream helmets $1978-87$ & 60 & $10(10)$ & 7 to 12 & $6(3.0)$ & 4 to 8 \\
\hline \multicolumn{6}{|l|}{ Ram car: } \\
\hline 1976 & 5 & $30(20)$ & 5 to 55 & $25(2.1)$ & 10 to 60 \\
\hline 1978 & 5 & $6(9)$ & 0 to 17 & $3(3.3)$ & 1 to 14 \\
\hline Quenching car, heater, and wharf station 1976 & 4 & 2 & 0 to 6 & $1(4.8)$ & 0.1 to 10 \\
\hline
\end{tabular}


Table 3 Descriptive statistics of personal measurements of carbonaceous particulates $\left(\mathrm{mg} / \mathrm{m}^{3}\right)$ for the coke side categories at the coke plant

\begin{tabular}{lccrl}
\hline Exposure group period & $\begin{array}{l}\text { Number of } \\
\text { measurements }\end{array}$ & $\begin{array}{l}\text { Arithmetic } \\
\text { mean }\end{array}$ & SD & 95\% CI \\
\hline Top oven 1974-76 & 19 & 16.2 & 18.2 & 7.4 to 25.0 \\
Side oven 1975-76,87 & 13 & 7.9 & 9.9 & 1.9 to 13.9 \\
Ram car 1975-76 & 8 & 6 & 2.3 & 3.7 to 7.6 \\
Quenching car 1975-76 & 3 & 0.9 & 0.4 & 0 to 1.8 \\
Wharf station 1975 & 8 & 4.1 & 2.9 & 1.7 to 6.5 \\
Coke screening 1974-81 & 48 & 13 & 17.8 & 7.8 to 18.2 \\
Coal treatment 1975-79 & 25 & 3.8 & 2.5 & 2.5 to 4.5 \\
\hline
\end{tabular}

When evaluating exposure to $\mathrm{CO}$, the categories were divided into exposed and not exposed (less exposed) with the presence of $\mathrm{CO}$ alarms at the workplaces as indicators of exposure. Faintings related to $\mathrm{CO}$ were used to define categories with peak exposures to CO.

The exposure to asbestos was assessed relative to the time the workers reported having been working in direct contact with the material. The benzene exposure was assessed with measurements and time spent in exposed areas. Heat stress was assessed relative to the time spent at the top of the ovens.

\section{MAINTENANCE WORKERS}

Measurements of PAHs and carbonaceous particulates were not available for the maintenance workers. The estimated exposures for these were based on the time weighted averages of coke oven workers after adjustments for the mean time the maintenance workers spent at the ovens. Time spent at the ovens was estimated from information in the questionnaires and from the interviews.

\section{Results}

Table 2 shows the arithmetic and geometric means of personal PAH measurements by exposure category and period not adjusted for the use of airstream helmets. Exposure to PAHs was highest for workers at the top of the ovens or close to its sides. Exposure control measures introduced in 1976 led to a substantial reduction in exposure for the top oven and side oven categories.

Table 3 shows the arithmetic means of personal measurements of carbonaceous particulates by exposure category and period. The estimates for carbonaceous particulates ranged from 1 to $16 \mathrm{mg} / \mathrm{m}^{3}$, with the highest exposure for workers at the top of the ovens and at the coke screening station.

Measures of variance in PAH exposure for the top oven category and the side oven category are shown in table 4 . The within worker or day to day variance was higher than the between worker variance. This indicated a larger difference in mean exposure between days (shifts) than the difference in mean exposure between workers in the same exposure category. The between worker variances were slightly higher inside the helmets than outside.

\section{ESTIMATION OF EXPOSURES}

fob exposure matrix

The job exposure matrix for the exposure variables PAHs, particulates, $\mathrm{CO}$, and benzene is shown in tables $5-7$ for the coke side, maintenance, and gas side categories, respectively. The estimates in the job exposure matrix do not match the means shown in table 2 as the estimates given in the matrix are adjusted for the use of airstream helmets. The tables also show the number of workers ever employed in the exposed categories. The number of workers ever employed in the other categories was 383. These other categories, which included laboratory, administration, and transport, were regarded as unexposed as work in these departments normally entailed no or very low exposures.

\section{Exposure to PAHs}

The interviews in this study as well as the measurement data from other plants ${ }^{78}$ indicated that oven workers at the sides and on the top experienced about the same exposure during the period of side charging. The side oven workers reported only minor changes in exposure after the rebuilding to top charging. The exposure estimates for the side oven category were therefore applied to all oven categories before 1970 .

Exposure to PAHs was highest for the top oven workers in the period 1970-6. Several exposure control measures were introduced towards the end of 1976. The sealing of the ovens was improved and the larry car and the ram car were equipped with filtered air. Air stream helmets were used from 1977 onwards by the workers at the top of the ovens and from 1978 onwards by the oven side workers. Top oven workers reported a mean use of an air stream helmet for about $75 \%$ (range $50 \%$ $100 \%$ ) of the time, whereas side oven workers reported a mean use for about $50 \%$ (range $20 \%-80 \%$ ) of the time. The mean efficiency of the helmets was calculated to be 0.67 (SD 0.26 ) based on parallel sampling inside and outside of the helmets $(n=212)$. The mean efficiency was calculated as the arithmetic mean $\mathrm{PAH}$ concentration inside the helmet divided

Table 4 Components of variance of exposure to PAHs between and within top oven and side oven workers (measurements outside and inside the airstream helmets)

\begin{tabular}{|c|c|c|c|c|c|c|}
\hline $\begin{array}{l}\text { Exposure category } \\
\text { (y) }\end{array}$ & $\begin{array}{l}\text { Measurements } \\
(n)\end{array}$ & $\begin{array}{l}\text { Workers } \\
(n)\end{array}$ & $\begin{array}{l}\text { GSD between } \\
\text { workers }\left({ }_{B W} S_{g}\right)\end{array}$ & $\begin{array}{l}\text { GSD within } \\
\text { workers }\left(\text { ww } S_{8}\right)\end{array}$ & $\begin{array}{l}\text { Ratio of the } 97.5 \\
\text { and the } 2.5 \\
\text { percentiles between } \\
\text { workers }\left({ }_{B W} R_{0.95}\right)\end{array}$ & $\begin{array}{l}\text { Systematic difference } \\
\text { between workers (\% of } \\
\text { total varience) } \\
{ }_{B W} S_{y 2}{ }_{T} S_{y 2} \times 100(\%)^{*}\end{array}$ \\
\hline \multicolumn{7}{|l|}{ Top oven $1978-87$ : } \\
\hline Outside helmet & 221 & 80 & 1.3 & 1.9 & 2.6 & 13 \\
\hline Inside helmet & 212 & 79 & 1.7 & 2.1 & 2.5 & 36 \\
\hline \multicolumn{7}{|c|}{ Side oven 1978-87: } \\
\hline Outside helmet & 67 & 33 & 1.1 & 2.5 & 1.9 & 2 \\
\hline Inside helmet & 55 & 30 & 1.2 & 2.3 & 2.0 & 7 \\
\hline
\end{tabular}

${ }_{B \mathrm{BW}} \mathrm{S}_{\mathrm{y} 2}$ is the variance between workers from the $\log$ transformed measurements, ${ }_{\mathrm{T}} \mathrm{S}_{\mathrm{y} 2}$ is the estimated total variance given by $\left({ }_{\mathrm{BW}} \mathrm{S}_{\mathrm{y} 2}{ }_{\mathrm{wWW}} \mathrm{S}_{\mathrm{y} 2}\right)$ where the $\mathrm{wWW}_{\mathrm{w} 2} \mathrm{~S}_{\mathrm{y} 2}$ is the variance between workers from the log transformed measurements. ${ }^{12}$ 
Table 5 Fob exposure matrix for the exposure variables PAH, carbonaceous particulates, $C O$, and benzene and number of workers ever employed in the respective categories at the coke side of the plant

\begin{tabular}{|c|c|c|c|c|c|}
\hline $\begin{array}{l}\text { Exposure category } \\
\text { (y) }\end{array}$ & $\begin{array}{l}\text { PAHs } \\
\left(\mu g / m^{3}\right)\end{array}$ & $\begin{array}{l}\text { Carbonaceous } \\
\text { particulates } \\
\left(\mathrm{mg} / \mathrm{m}^{3}\right)\end{array}$ & $\begin{array}{l}C O \\
(\text { exposed }=1)\end{array}$ & $\begin{array}{l}\text { Benzene } \\
(\text { exposed = 1) }\end{array}$ & $\begin{array}{l}\text { Workers ever } \\
\text { employed in the } \\
\text { category (n) }\end{array}$ \\
\hline \multicolumn{6}{|l|}{ Top oven: } \\
\hline $1964-70$ & 45 & 2 & 1 & 1 & \multirow[t]{3}{*}{106} \\
\hline $1971-76$ & 300 & 16 & 1 & 1 & \\
\hline $1977-88$ & 65 & 3 & 1 & 1 & \\
\hline \multicolumn{6}{|l|}{ Side oven: } \\
\hline 1964-77 & 45 & 8 & 1 & 1 & \multirow[t]{2}{*}{59} \\
\hline $1978-88$ & 35 & 5 & 1 & 1 & \\
\hline \multicolumn{6}{|c|}{ Stamper and ram car: } \\
\hline $1964-70$ & 45 & 8 & 1 & 1 & \multirow[t]{3}{*}{31} \\
\hline $1971-76$ & 30 & 6 & 1 & 1 & \\
\hline $1977-88$ & 6 & 1 & 1 & - & \\
\hline \multicolumn{6}{|c|}{ Heater and quenching car: } \\
\hline $1964-88$ & 2 & 1 & - & - & 78 \\
\hline \multicolumn{6}{|l|}{ Wharf station: } \\
\hline 1964-88 & 2 & 4 & - & - & 27 \\
\hline \multicolumn{6}{|l|}{ General oven: } \\
\hline 1964-70 & 40 & 5 & 1 & 1 & \multirow[t]{3}{*}{99} \\
\hline $1971-76$ & 150 & 9 & 1 & 1 & \\
\hline 1977-88 & 40 & 6 & 1 & 1 & \\
\hline \multicolumn{6}{|l|}{ Coal treatment: } \\
\hline $1954-88$ & - & 4 & - & - & 74 \\
\hline \multicolumn{6}{|l|}{ Coke screening: } \\
\hline $1964-88$ & - & 13 & - & - & 55 \\
\hline \multicolumn{6}{|l|}{ General coke side: } \\
\hline $1964-70$ & 20 & 6 & 1 & 1 & \multirow[t]{3}{*}{64} \\
\hline $1971-76$ & 80 & 9 & 1 & 1 & \\
\hline 1977-88 & 20 & 5 & 1 & 1 & \\
\hline \multicolumn{6}{|c|}{ Supervisor coke side: } \\
\hline 1964-70 & 10 & 3 & 1 & 1 & \multirow[t]{3}{*}{15} \\
\hline $1971-76$ & 40 & 5 & 1 & 1 & \\
\hline $1977-88$ & 10 & 3 & 1 & 1 & \\
\hline
\end{tabular}

Exposure estimates based on measurements are indicated in bold characters and estimates assigned are indicated in italics.

- $=$ Regarded as unexposed.
Exposure to $C O$, arsenic, benzene, asbestos, and heat

Measurements of CO were performed in 1975 but were of little value as exposure often was due to occasional leakages and therefore varied considerably. From 1967 there was a continuous surveillance of leakages from $30 \mathrm{CO}$ monitoring points. The surveillance points indicated zones where exposure to $\mathrm{CO}$ was likely to occur. All exposure categories were classified as exposed to $\mathrm{CO}$ if they entailed work for more than 10 hours a week in zones where CO surveillance existed. Measurements suggested an $8 \mathrm{~h}$ TWA exposure for these categories of between 10 and $30 \mathrm{ppm}$. At the area for ammonia synthesis, at the cracking station, and in the compressor hall, leakages from a gas pipe containing $70 \%$ CO could lead to high exposures to CO. Fourteen of a total of 20 self reported faintings at the gas side of the plant, occurred in these areas. The faintings indicated peak exposures of several $100 \mathrm{ppm}$, and workers in these areas were defined as exposed to peak CO concentrations.

The potential for arsenic exposure was negligible except during the mixing of arsenic in the sulphur cleaning department. The workers used masks with dust filters and protective clothing. Nine personal short time measurements during arsenic mixing in the sulphur cleaning department indicated a mean arsenic exposure of $0.2 \mathrm{mg} / \mathrm{m}^{3}$ outside the mask. Assuming $80 \%$ protection when using a mask and 4.5 hours of mixing weekly, the workers with the highest exposure received an $8 \mathrm{~h}$ TWA exposure to arsenic of about $5 \mu \mathrm{g} / \mathrm{m}^{3}$. Exposure categories involved in arsenic mixing were classified as exposed to arsenic.

Exposure to benzene was probably highest at the benzene distillation area before 1969 and at the top of the coke ovens after 1970. From 1969 the exposure at the benzene distillation area was reduced due to automatisation of the process. As no reliable measurements existed for the exposed groups it was impossible to measure the relative differences between the exposure categories. These, and other categories where exposure was confirmed by benzene measurements, were therefore classified as exposed and all others as unexposed. The benzene measurements suggested an exposure between 0.1 and $3 \mathrm{ppm}$ for the exposed categories after 1970 .

Bricklayers were exposed to asbestos (mainly chrysotile) for an average of 2.5 hours a week and were assigned as exposed to asbestos. Maintenance personnel and the workers at the gas cracking station reported a mean exposure 1976 at the coke ovens was multiplied by the $\mathrm{PAH}$ exposures at the coke ovens after 1976.

, carbonaceous particulates, $C O$, and benzene and number of

Table 6 fob exposure matrix for the exposure variables workers ever employed in the maintenance categories

\begin{tabular}{|c|c|c|c|c|c|}
\hline Exposure category $(y)$ & $\begin{array}{l}\text { PAHs } \\
\left(\mu g / m^{3}\right)\end{array}$ & $\begin{array}{l}\text { Carbonaceous } \\
\text { particulates } \\
\left(\mathrm{mg} / \mathrm{m}^{3}\right)\end{array}$ & $C O($ exposed $=1)$ & $\begin{array}{l}\text { Benzene } \\
\text { (exposed =1) }\end{array}$ & $\begin{array}{l}\text { Workers ever } \\
\text { employed in the } \\
\text { category (n) }\end{array}$ \\
\hline General maintenance $1964-88$ & 3 & 1 & - & - & 61 \\
\hline Coke side maintenance $1964-88$ & 10 & 2 & 1 & 1 & 58 \\
\hline Bricklayers and oven rebuilders $1964-88$ & 25 & 5 & 1 & 1 & 41 \\
\hline Gas side maintenance $1964-88$ & - & 1 & 1 & 1 & 30 \\
\hline Insulators $1964-88$ & - & 2 & - & - & 7 \\
\hline
\end{tabular}

Insulators $1964-88$

$-=$ Regarded as unexposed. 
Table 7 Fob exposure matrix for the exposure variables PAHs, carbonaceous particulates, $C O$, and benzene and number of workers ever employed in the respective categories at the gas side of the plant

\begin{tabular}{|c|c|c|c|c|c|}
\hline Exposure category $(y)$ & $\begin{array}{l}P A H s \\
\left(\mu g / m^{3}\right)\end{array}$ & $\begin{array}{l}\text { Carbonaceous } \\
\text { particulates } \\
\left(\mathrm{mg} / \mathrm{m}^{3}\right)\end{array}$ & $\begin{array}{l}C O \\
(\text { exposed }=1)\end{array}$ & $\begin{array}{l}\text { Benzene } \\
\text { (exposed = 1) }\end{array}$ & $\begin{array}{l}\text { Workers ever } \\
\text { employed in the } \\
\text { category }(n)\end{array}$ \\
\hline General gas side $1964-88$ & - & - & 1 & 1 & 62 \\
\hline Gas cleaning and tar destillery $1964-88$ & - & - & 1 & 1 & 127 \\
\hline Ammonia synthesis $1964-87$ & - & - & 1 & - & 85 \\
\hline Cracking station $1964-87$ & - & - & $1^{\star}$ & 1 & 36 \\
\hline \multicolumn{6}{|l|}{ Compressor hall: } \\
\hline 1964-78 & - & - & $1^{\star}$ & - & 23 \\
\hline $1979-88$ & & - & 1 & - & \\
\hline
\end{tabular}

^Peak exposure for carbon monoxide.

- Regarded as unexposed.

to asbestos between half an hour to one hour weekly and were also classified as exposed.

Heat stress was associated with heat radiation from the coke ovens. Top side coke oven workers and bricklayers were assigned a relative level of five. As the workers in the general oven category worked for about one fifth of their time at the top, they were assigned a level of one. Other workers were also exposed to heat, but normally over shorter periods. These were therefore assigned as not exposed to heat.

\section{Discussion}

In this study we have estimated the historical exposure to PAHs, carbonaceous particulates, $\mathrm{CO}$, asbestos, benzene, heat, and quartz for later use in epidemiological studies of cancer incidence and mortality. The exposure of greatest concern in this study is PAHs, but exposures to carbonaceous particulates and CO may also be of importance. The main limitations of this study are the lack of measurements before 1975, the total lack of measurements for some of the exposed categories (maintenance workers) and the lack of representative measurements for some of the agents (CO, arsenic, benzene, and asbestos). The lack of measures for dermal uptake of PAHs is also a weakness of this study. Despite these limitations, we think that the exposure estimates reflects the actual exposures for most of the former employees. The exposure assessment thus provides a reasonable tool for the estimation of dose-response relations in the subsequent epidemiological analyses and for future epidemiological follow up studies.

Some degree of subjective evaluation is unavoidable when estimating historical exposures in the absence of measurement data. Studies of the validity of subjective quantitative estimations suggest that raters are able to rank the different jobs within a plant, but that quantitative estimates are uncertain. Provision of a few measurements improved the quantitative estimation substantially. ${ }^{15}{ }^{16}$ In the present study some exposure levels were estimated on the basis of a few measurements, on the time exposed, and on subjective and qualitative information. These estimates may be difficult to compare with estimates from other plants and exposures elsewhere, but they may be useful in distinguishing between differently exposed people in an epidemiological study.

REPRESENTATIVENESS OF THE MEASUREMENTS Polycyclic aromatic hydrocarbons were sampled on membrane filters and analysed by gas chromatography until 1980 when this method was replaced by thin layer chromatography. The change in method has probably not affected the results, as no notable change in exposure could be found between 1978-9 and 1980-1.

Positive bias caused by the use of short time sampling, worst case sampling, compliance sampling, and deliberate contamination, has been proposed as a special problem when assessing historical measurements. ${ }^{17}{ }^{18}$ Such bias will vary under different conditions and between jobs and between exposure agents. Some of the estimates in this study, especially those in the smaller exposure categories with few measurements, are probably affected by such bias. The use of only long term measurements for measurement of exposure in the present study, and the avoidance of measurements sampled after spills or after complains will however limit such bias. We conclude that the sampling and analyses of both particulate PAHs and carbonaceous particulates seemed to be representative for the actual conditions over time. The sampling of $\mathrm{CO}$ and benzene were probably less representative for the actual conditions due to few samples and due to uncertain reasons for sampling.

EXPOSURE TO PAHS

The estimates of the exposures at the ovens before 1971 are particularly uncertain because no sampling was performed during the side filling period.

The analyses of variance of exposures to PAHs are based on the assumption of random sampling and stationary conditions. ${ }^{19}$ As the measurements were sampled over several years (1978-87) there may be a problem of nonstationary conditions, but the exposure and production process did not change notably in this period.

The assumption of random sampling may also be a problem, but the measurements were not sampled on special occasions nor on specially selected people. Thus, the distribution of the measurements may be regarded as representative for the actual variation of exposure.

We adjusted the exposure estimates for the use of air stream helmets. However, this may underestimate the systemic dose as skin contamination will also contribute. ${ }^{20} 21$

Owing to the work practices, the face piece of the helmet had not always been locked during measurements inside the helmet. The meas- 
urements, therefore, indicated a lower protection factor than obtained under ideal use.

The assumption that all workers at the top of the ovens and at the sides used the air stream helmets for the same duration of time is obviously incorrect. The between worker variation of exposure may therefore have been higher than estimated (table 4).

The uniformity of the categories as measured by ${ }_{\text {вw }} \mathrm{R}_{0.95}$ was 2.6 for the top oven category and 1.9 for the side oven category. These values suggest a high uniformity compared with estimates of other occupational groups with outdoor exposure to particulates, ${ }^{22}$ and are close to the definition made by Rappaport for uniformly exposed groups $\left({ }_{\mathrm{BW}} \mathrm{R}_{0.95}<2\right) .{ }^{11}$

Benzene soluble organic material is used as a measure for coal tar pitch volatiles (CTPV) in the United States and in the United Kingdom. Benzene soluble organic material can be compared with particulate PAHs by multiplying the concentrations of PAHs by a factor of 5 , as the $\mathrm{PAH}$ content in benzene soluble organic material is $10 \%-40 \%$ with $20 \%$ as a typical value. ${ }^{9}$ Under this assumption, concentrations of coal tar pitch volatiles at the study plant between 1970 and 1976 were about half those measured at 10 coke plants in the United States in $1967 .{ }^{5}$ They were also lower than concentrations measured at coke plants in the United Kingdom. ${ }^{8}$ A more recent study from one United States plant showed concentrations of coal tar pitch volatiles comparable with those at the study plant. ${ }^{6}$ The ranking of the exposed jobs at the ovens is similar in the different studies. ${ }^{568}$ The reasons for the differences in exposure between plants may be different production processes, different climatic conditions, and the unequal introduction of exposure control measures. Different methods of sampling and analysis are also important factors. ${ }^{23}$ A reason for the possibly higher concentrations of coal tar pitch volatiles in the United States may be process factors-such as higher oven wall temperatures, faster coking rates and the use of coal with a higher content of volatile matter, and less moisture. ${ }^{24}$

\section{IMPACT ON THE EPIDEMIOLOGICAL STUDY}

In the epidemiological study cumulative exposure was chosen as a surrogate for dose and calculated for each year under observation as the product of duration and exposure summed for all jobs held. Arithmetic means were used for the calculation of cumulative exposure as this measure probably reflects the dose accumulated over time for a group of workers experiencing relatively large day to day variations compared with the variation between the people in the exposure group.

A correlation analysis between the agents in the different exposure categories and between cumulative exposure and duration of exposure was performed to evaluate possible impacts on the epidemiological study. The strongest correlation between the agents was seen between PAHs and carbonaceous particulates (correlation coefficient $=0.7$ ) and between PAHs and heat (correlation coefficient $=0.6$ ). The correla- tion coefficients between the other agents were $<0.35$. The correlation coefficients between duration of work and cumulative exposure to PAHs and carbonaceous particulates were 0.1 and 0.3 , respectively. The correlation coefficients between duration of exposed work and cumulative exposure to PAHs and carbonaceous particulates were 0.6 and 0.8 , respectively.

This study was financed by the Norwegian Ministry of Oil and Energy.

1 Stewart PA. Assessing occupational exposures in epidemiology studies. In: Keynote addresses, 24th Congress of the International Commission on Occupational Health. Nice: ICOH, 1993:137-49.

2 Seixas NS, Checkoway H. Exposure assessment in industry specific retrospective occupational epidemiology studies. Specific retrospective occupational epid

3 Kaupinnen TP. Assessment of exposure in occupational epidemiology. Scand $\mathcal{f}$ Work Environ Health 1994;20(special issue):19-29.

4 International Agency for Research on Cancer. IARC monographs on the evaluation of the carcinogenic risk of chemicals to humans. Vol 34. Polynuclear aromatic compounds, part 3, Industrial exposures in aluminium production, coal gasification, coke production and iron and steel founding. Lyon, Feance: IARC, 1984

5 Fannick N, Gonshor LT, Shockley J. Exposure to coal tar pitch volatiles at coke ovens. Am Ind Hyg Assoc f 1972;33. 461-8.

6 Keimig GD, Slymen DJ, White O. Occupational exposure to coke oven emissions from 1979-83. Arch Environ Health 1986;41:363-7.

7 Hurley JF, Cherrie JW, Maclaren WM. A 20-year follow up of the mortality of coke workers in Britain. London: Institute of Occupational Medicine, February 1991. (IOM Report TM/91/01.)

8 Davis GM, Hodkinson A, DiVetta P. Measurement and analysis of occupational exposures to coke oven emissions. Ann Occup Hyg 1986;30:51-62.

9 Bjorseth A, Bjorseth O, Fjeldstad PK. Polycyclic aromatic hydrocarbons (PAH) in working atmospheres II. Determination of PAH content in a coke plant. Scand 7 Work Environ Health 1978;4:224-36.

10 Intercalibrating of polycyclic aromatic hydrocarbons. Oslo, Norway: Institute of Occupational Health, 1981. (In Norwegian, Report No: HD 864/81.)

11 Rappaport SM. Assessment of long-term exposures to toxic substances in air. Ann Occup Hyg 1991;35:61-121.

12 Rappaport SM. Intepreting levels of exposures to chemical agents. In: Harris RL, Cralley LJ, Cralley LV, eds. Patty's industrial hygiene and toxicology. Theory and rationale of industrial hygiene practice: the work environment. Vol III, part A, 3rd ed. New York: John Wiley 1994:349-405.

13 Kromhout H, Heederik D. Occupational epidemiology in the rubber industry: implication of exposure variability. $A m$ f Ind Med 1995;27:171-85.

14 Kromhout H, Loomis DP, Mihlan GJ, et al. Assessment and grouping of occupational magnetic field exposure in five electric utility companies. Scand $\mathcal{f}$ Work Environ Health 1995;21:43-50.

15 Kromhout H, Oostendorp Y, Heederik D, et al. Agreement between qualitative exposure estimates and quantitative between qualitative exposure estimates and quantitative

16 Hawkins NC, Evans SE. Subjective estimation of toulene exposures: a calibration study of industrial hygienists. Appl Ind Hyg 1989;4:61-8.

17 Ulfvarson U. Limitation to the use of employee exposure data on air contaminants in epidemiologic studies. Int Arch Occup Environ Health 1983;52:285-300.

18 Olsen E, Laursen B, Vinzents PS. Bias and random errors in historical data of exposure to organic solvents. Am Ind Hy Assoc F 1991;52:204-11.

19 Symanski E, Kupper LL, Kromhout H, et al. An investigation of systematic changes in occupational exposure. Am Ind Hyg Assoc F 1996;57:724-35.

20 VanRooij JGM, Bodelier Bade MM, Jongeneelen FJ. Estimation of individual dermal and respiratory uptake of Estimation of individual dermal and respiratory uptake of polycyclic aromatic hydrocarbo

21 VanRooij JGM, Bodelier Bade MM, Hopmans PM, et al. Reduction of urinary 1-hydroxypyrene excretion in cokeoven workers exposed to polycyclic aromatic hydrocarbon due to improved hygienic skin protective measures. Ann Occup Hyg 1994;30:247-56.

22 Kromhout H, Symanski E, Rappaport SM. A comprehensive evaluation of within and between worker components of occupational exposure to chemical agents. Ann Occup Hyg 1993;37:253-70.

23 Leinster P, Evans MJ. Factors affecting the sampling of airborne polycyclic aromatic hydrocarbons-A review. Ann borne polycyclic aromatic hyd

24 Doherty JD, De Carlo JA. Coking practice in the United States compared with some western European practices. Blast Furnace and Steel Plant 1967;55:141-56. 